\title{
Ensino remoto sobre processo de enfermagem na pandemia da Covid-19: Relato de experiência
}

\author{
Remote teaching about nursing process in the covid-19 pandemic: Experience report \\ Enseñanza remota sobre el proceso de enfermería en la pandemia covid-19: Informe de experiencia
}

Recebido: 20/05/2021 | Revisado: 28/05/2021 | Aceito: 30/05/2021 | Publicado: 14/06/2021

\author{
Alessandra Conceição Leite Funchal Camacho \\ ORCID: https://orcid.org/0000-0001-6600-6630 \\ Universidade Federal Fluminense, Brasil \\ E-mail: cicacamacho@gmail.com \\ Vitória Meireles Felipe de Souza \\ ORCID: https://orcid.org/0000-0002-1129-6324 \\ Universidade Federal Fluminense, Brasil \\ E-mail: vifelipe@id.uff.br \\ Harlon França de Menezes \\ ORCID: https://orcid.org/0000-0001-9884-6511 \\ Universidade Federal Fluminense, Brasil \\ E-mail: harlonmenezes@hotmail.com
}

\begin{abstract}
Resumo
Objetivo: descrever as estratégias de planejamento e o desenvolvimento do ensino remoto sobre o processo de enfermagem na Pandemia da COVID-19. Metodologia: trata-se de um relato de experiência acerca das estratégias de ensino remoto empreendidas na disciplina de Fundamentos de Enfermagem III sobre o Processo de Enfermagem com período de coleta de dados de Julho a Novembro de 2020. A análise realizada foi do tipo descritiva. Resultados: A interatividade no ensino remoto foi fundamental para o planejamento contínuo do ambiente virtual por meio do uso de ferramentas e aplicativos frente ao isolamento social imposto pela Pandemia. Conclusão: a possibilidade de buscar a interatividade na educação remoto nos seguintes aspectos: planejamento contínuo; o docente como aquele que faz a mediação do conhecimento; combinação do ambiente virtual de aprendizagem com as necessidades atuais do ensino remoto.
\end{abstract}

Palavras-chave: Enfermagem; Coronavirus; Tecnologia.

\begin{abstract}
Objective: to describe the planning strategies and the development of remote education on the nursing process in the COVID-19 Pandemic. Method: this is an experience report about the remote teaching strategies undertaken in the discipline of Fundamentals of Nursing III on the Nursing Process with data collection period from July to November 2020. The analysis performed was of the descriptive type. Results: interactivity in remote education was essential for the continuous planning of the virtual environment through the use of tools and applications in the face of the social isolation imposed by Pandemia. Final considerations: the possibility of seeking interactivity in remote education in the following aspects: continuous planning; the teacher as the one who mediates knowledge; combining the virtual learning environment with the current needs of remote education.
\end{abstract}

Keywords: Nursing; Coronavirus; Tecnology.

\section{Resumen}

Objetivo: describir las estrategias de planificación y desarrollo de la educación a distancia sobre el proceso de enfermería en la Pandemia COVID-19. Método: se trata de un relato de experiencia sobre las estrategias de enseñanza a distancia emprendidas en la disciplina de Fundamentos de Enfermería III sobre el Proceso de Enfermería con un período de recolección de datos de julio a noviembre de 2020. El análisis realizado fue descriptivo. Resultados: la interactividad en la educación a distancia fue fundamental para la planificación continua del entorno virtual mediante el uso de herramientas y aplicaciones frente al aislamiento social impuesto por Pandemia. Consideraciones finales: la posibilidad de buscar la interactividad en la educación a distancia en los siguientes aspectos: planificación continua; el maestro como mediador del conocimiento; combinando el entorno de aprendizaje virtual con las necesidades actuales de educación a distancia.

Palabras clave: Enfermería; Coronavirus; Tecnología. 


\section{Introdução}

O novo coronavírus denominado como Severe Acute Respiratory Syndrome Coronavirus-2 (Sars-Cov-2), é capaz de ocasionar a doença chamada de Corona Virus Disease-19 (COVID-19). Destaca-se que tal doença constitui quadro clínico que pode variar de infecções assintomáticas a quadros respiratórios graves. Conforme Organização Mundial de Saúde (OMS) 80\% dos pacientes com COVID-19 podem ser assintomáticos e aproximadamente 5\% podem necessitar de suporte para o tratamento de insuficiência respiratória (Ministério da Saúde, 2020).

No cenário mundial a doença respiratória chamada COVID-19, ocasionado pelo novo coronavírus SARS-CoV-2, foi denominada como uma pandemia em 11 de março de 2020, pela Organização Mundial da Saúde (OMS, 2019). Já no Brasil, o Ministério da Saúde expôs em 03 de fevereiro de 2020, a emergência em Saúde Pública de Importância Nacional (ESPIN) e posteriormente, sancionou a lei $\mathrm{n}^{\circ} 13.979$ de 6/2/20202, que dispõe sobre as medidas para enfrentamento da emergência, de importância de caráter nacional e internacional, devido a COVID-19. No mês seguinte, por meio da Portaria $\mathrm{n}^{\circ} 454$ de 20/3/20203, o Brasil declarou a situação de transmissão comunitária no território nacional, a vista disso, as ações de quarentena, isolamento e distanciamento social se tornaram imprescindíveis (Lima et al., 2020).

Desse modo, se realizam no Brasil ações de isolamento e distanciamento social a fim de prevenir a propagação da COVID-19. Dentre essas medidas, destaca-se a suspensão das aulas a atividades presenciais pelas instituições de ensino (Camacho, Joaquim, Menezes, \& Sant'Anna, 2020). Isso porque o distanciamento social trata-se de uma estratégia possibilita o isolamento de casos, a quarentena dos contatos, assim como a prática de não frequentar ambientes que apresentem aglomerações de indivíduos (Qualls et al., 2017).

Tal situação demonstra efetividade no controle do crescimento da doença. Destaca-se que essa medida é capaz de resguardar os sistemas de saúde do colapso devido à elevada demanda, sobretudo relacionado a disponibilidade de leitos de terapia intensiva (Ferguson et al., 2020). Esse distanciamento fortaleceu o aprendizado mediado por tecnologias. Tal fato se deve pelas aplicações inovadoras que permitem novos paradigmas para produção do conhecimento por meio do uso de ferramentas digitais e de interações sociais não presenciais (Carneiro, Rodrigues, França, \& Prata, 2020).

Diante dessa situação delicada, o Ministério da Educação, publicou a Portaria no 343, de 17 de março de 2020 que dispõe sobre a substituição das aulas presenciais por aulas em meios digitais durante a pandemia da COVID-19. Essa portaria determina a responsabilidade das instituições de ensino na definição das disciplinas de maneira remota, a disponibilização de ferramentas aos alunos que possibilitem o acompanhamento dos conteúdos oferecidos, bem como a efetuação das avaliações durante o período da autorização (Ministério da Educação, 2020). A partir disso, as instituições universitárias do Brasil se readequaram conforme a própria velocidade na tentativa de fornecer a continuidade do ensino na graduação diante do novo cenário instalado pela pandemia (Fernandes, 2021),

As instituições de ensino superior no país realizaram seus respectivos planejamentos de retorno das atividades acadêmicas e administrativas de forma remota dando a oportunidade de discussões sobre essa modalidade de ensino e de novas experiências voltadas para a capacitação do professor (Camacho, 2020).

Considerando as ações de enfrentamento à pandemia da COVID-19, a Universidade Federal Fluminense (UFF) publicou a resolução n.160 de 2020 pelo Conselho de Ensino, Pesquisa e Extensão. Nessa resolução as atividades mediadas por tecnologias digitais, no contexto da pandemia, deveriam apresentar concepção didático-pedagógica que visa atender uma mudança temporária para um modo de ensino alternativo, por meio de atividades em ambiente remoto, mediadas por tecnologias (UFF, 2020).

Diante dessa realidade, a disciplina de Fundamentos de Enfermagem III foi planejada para o ensino remoto mediado por tecnologias voltado para o ensino de graduação em Enfermagem. No que cerne ao contexto deste relato a descrição é voltada para o ensino remoto do Processo de Enfermagem através de conteúdos interativos e informativos. 
$\mathrm{O}$ processo de enfermagem precisa ser efetuado em todos os ambientes que aconteça o cuidado profissional de Enfermagem de maneira deliberativa e sistemática. Portanto, se organiza em cinco etapas inter-relacionadas, interdependentes e recorrentes: Coleta de Dados de Enfermagem (histórico de enfermagem), Diagnóstico de Enfermagem, Planejamento de Enfermagem, Implementação e Avaliação de Enfermagem (COFEN, 2009). A vista disso, o enfermeiro necessita estar preparado adequadamente para realizar o processo de enfermagem, visto que contribui para o atendimento integral das necessidades do paciente de forma eficiente. Diante do exposto estabeleceu-se o seguinte objetivo deste artigo: descrever as estratégias de planejamento e o desenvolvimento do ensino remoto sobre o processo de enfermagem na Pandemia da COVID19.

\section{Metodologia}

Trata-se de um relato de experiência que descreve o período de planejamento, construção e implementação do conteúdo do ensino remoto sobre o processo de enfermagem através de uma abordagem interativa e informativa na disciplina de Fundamentos de Enfermagem III da Universidade Federal Fluminense, no período de Setembro a Novembro de 2020, e foi realizada a avaliação discente referente a disciplina no período Novembro de 2020 com a análise do tipo descritiva.

Apresenta abordagem qualitativa e acadêmica, realizada a partir de dados coletados diretamente no contexto de determinado acontecimento, por meio da utilização da metodologia de estudos de fenômeno social. Além disso, se caracteriza como estudo de caso, uma vez que, descreve e analisa de forma mais detalhada possível, algum caso que apresente determinada particularidade que o torna especial. (Pereira, Shitsuka, Parreira, \& Shitsuka, 2018). Portanto, o presente artigo trata sobre o ensino remoto acerca do processo de enfermagem no contexto da pandemia da COVID-19.

No Ambiente Virtual de Aprendizagem (AVA) foram disponibilizados o pacote Gsuíte com vários aplicativos para o desenvolvimento do ensino remoto no Google tais como o: Meet, Classroom, Docs, Planilhas, Apresentações, Agenda, Jamboard entre outros visando a interatividade e a criatividade. E como estrutura organizacional foram então utilizadas a Plataforma Google Classroom para atividades assíncronas (fóruns de discussões; vídeos; leitura de artigos entre outros) e também a Plataforma Google Hangouts Meet para atividades síncronas (aulas, palestras e lives).

O conteúdo teórico da disciplina foi especificado por datas e título das aulas de acordo com o cronograma da disciplina para auxiliar na visualização do discente. As avaliações foram desenvolvidas ao longo da disciplina por meio da participação em sala de aula virtual; participação nas aulas remoto e a construção de atividades interativas com enfoque na processo de enfermagem.

Quanto aos aspectos éticos, este relato de experiência atende a Resolução nº 510, de 07 de 2016 do Conselho Nacional de Saúde em seu artigo primeiro em seu Parágrafo único.

\section{Resultados}

A modalidade de ensino remoto sobre o processo de enfermagem teve por finalidade o de facilitar o processo de aprendizagem e quando da estrutura organizacional foi o de promover o engajamento discente, a fim de potencializar a sua participação e o aprendizado. Desta forma, os tópicos elencados para organizar a disciplina ficaram distribuídos por datas com o seu início de apresentação da disciplina organizado no "Mural" e no item "Atividades" do Ambiente Virtual de Aprendizagem (AVA).

Aponta-se a elaboração nas disciplinas no item "Ambientação" (Apresentação da Disciplina) conteúdos explicativos que foram disponibilizados uma semana antes do início das aulas para que os discentes pudessem apreender sobre o AVA. 
Nesse item de ambientação foram fornecidos: o cronograma e o plano remoto da disciplina; três vídeos sendo um sobre a apresentação da disciplina e dois vídeos que explicam de forma didática sobre como o aluno deve acessar e estudar no AVA.

De forma subsequente, os demais conteúdos da disciplina foram organizados por datas de acordo com o plano remoto da disciplina e utilizando ferramentas interativas de aprendizagem no item "Atividades". A construção da disciplina nos forneceu a oportunidade de novas experiências onde buscamos refletir sobre o ensino remoto. Assim, o planejamento foi direcionado para a disponibilidade de conteúdos que possibilitassem diminuir dúvidas como destaque ao design instrucional para melhor compreensão do Ambiente Virtual de Aprendizagem.

Destaca-se a disponibilidade de um tópico específico com postagens dos conteúdos das aulas: como vídeos gravados sobre as aulas, textos sobre Processo de Enfermagem bem como conteúdos interativos através de Padlet e Jamboard. Também foram criados tópicos para que os discentes pudessem interagir e retirar as dúvidas sobre as aulas remotas e o próprio material de estudo.

Cabe destacar o desenvolvimento de uma atividade avaliativa onde o discente realizou um relatório que descrevesse sobre os pontos do texto indicado que coadunasse com a aula ministrada via remoto pelo Meet. Além disso, buscando a interatividade também foi elaborada uma atividade interativa onde os discentes construíram um texto autoral sobre a aula síncrona em consonância com os conteúdos disponibilizados.

Essas atividades planejadas e implementadas estão pautadas no Plano Pedagógico Institucional da Universidade que tem estruturado suas metodologias pelo paradigma da modernidade, na qual as sociedades atuais estão a exigir, cada vez mais, a participação de cidadãos não somente qualificados para o trabalho, mas principalmente aptos a refletir e produzir novos conhecimentos acerca de sua prática profissional.

Para avaliação final da disciplina foi elaborado um formulário de avaliação da disciplina remoto pelos discentes. Dos 15 alunos que devolveram o formulário somente 11 discentes responderam. A avaliação foi amplamente divulgada no mural do AVA e por e-mail nos contatos dos alunos via AVA.

Os discentes responderam sobre o formato online da disciplina, o qual foi distribuído em aulas síncronas e assíncronas e, 18,2\% atribuíram a disciplina remoto como excelente, 36,4\% como bom, 27,3\% como regular e 18,2\% como ruim. Já no item de avaliação sobre o design instrucional e organizacional para acompanhar a disciplina, 90,9\% foi positiva e $9,1 \%$ tiveram dificuldades. Quanto a autoavaliação discente sobre organização para cumprimento das atividades das disciplinas 54,5\% afirmaram que foi positiva sua organização e 45,5\% afirmaram que foi difícil a sua organização neste período de ensino remoto.

Ainda sobre a autoavaliação discente houve a pergunta se o aluno refletiu sobre a educação mediada pela tecnologia, considerando o contexto atual, os serviços disponíveis no ambiente virtual e as abordagens pedagógicas: 90,9\% afirmaram que fizeram essa reflexão e 9,1\% não efetuaram essa reflexão.

Destaca-se que durante a vigência da disciplina ocorreu a necessidade de flexibilização de horários, gravação das transmissões online das aulas para que os alunos pudessem ter acesso dos conteúdos em outros momentos. Isso deu também maior oportunidade de flexibilidade no controle de frequência dos alunos através do acesso dos mesmos no AVA.

\section{Discussão}

A transição do ensino remoto de emergência, essencial na primeira fase, para uma educação digital em rede de qualidade se torna imprescindível. Observa-se a necessidade de criação de modelos de aprendizagem virtuais que incorporem processos de desconstrução e que possibilitam ambientes de aprendizagem colaborativos e construtivistas nas plataformas selecionadas (Monteiro, Moreira, \& Almeida, 2012; Moreira, 2012; Moreira, 2018 apud Moreira, Henrique, \& Barros, 2020). 
As mudanças no sistema educacional devido a pandemia da COVID-19, precisaram ser efetuadas rapidamente, assim, os professores necessitaram transpor conteúdos e adaptar as aulas presenciais para plataformas online com o emprego das Tecnologias Digitais da Informação e Comunicação (TDIC) (Rondini, Pedro, \& Duarte, 2020).

Como maneira de verificação do processo de ensino aprendizagem contínua é possível identificar formas de contato efetivas pelo registro das funcionalidades do AVA, como a participação e discussões nas aulas remoto síncrona e nas atividades assíncronas, nos feedbacks das atividades e nas contribuições dentro do ambiente (disponíveis no mural, nos fóruns de debates e nas postagens das atividades) (Camacho, 2020).

Nesta perspectiva, os conteúdos de multimídia elaborados pelos docentes e fornecidos através de textos, vídeos e inserção de anexos, possibilitam a criação da tarefa na hora ou programadas, de forma a tornar eficiente para as disciplinas de curta ou longa duração. Diante disso, os discentes são convidados a efetuar as tarefas, sendo avaliados pelo docente no próprio AVA (Camacho, 2020).

O ensino remoto deve ser visto como um aliado no curso de graduação em Enfermagem na disciplina de Fundamentos de Enfermagem III e não como uma atividade substitutiva neste período de Pandemia. O ensino remoto como método não consiste apenas em apresentação de textos, vídeos, fóruns e outros aplicativos, mas deve ser visto como uma maneira de analisar a motivação e o comportamento do aluno diante do desafio do aprendizado colaborativo (Teixeira, Lage, Junior, Corradi, \& Oliveira, 2020).

A construção da interatividade no ensino remoto foi fundamental para o planejamento contínuo do ambiente virtual através do uso de ferramentas e aplicativos na disciplina de Fundamentos de Enfermagem III frente ao isolamento social imposto pela Pandemia.

O ensino remoto exige criatividade dos docentes para promoção de discussões junto aos discentes sobre o conteúdo. Além disso, destaca-se a importância de: disciplina (horário e dedicação), disponibilizar vídeos explicativos, interação e adequação do ambiente virtual de aprendizagem (Bastos et al., 2020). Soma-se a isso, torna-se evidente o papel do docente no entanto não se trata de um agente exclusivo da produção do conhecimento, uma vez que o estudante precisa ser compreendido e estimulado a ser também responsável por sua formação intelectual (Castaman \& Rodrigues, 2020).

Nesse sentido, a Enfermagem, deve compartilhar da perspectiva de saúde como qualidade de vida e proteção frente ao novo coronavírus, da participação e do controle social, da integralidade das ações de saúde individual e coletiva e, por fim, da inclusão à educação (Costa et al., 2020). O ensino remoto deve ser inclusivo respeitando as diferenças, propondo medidas que assegure melhoria da qualidade da educação, o investimento com ampla formação dos educadores, a previsão e provisão de recursos materiais e humanos.

Essa situação vivenciada provocou mudanças pelas instituições de ensino na área da saúde, com novas formas de ensinar discutindo sobre as diferentes abordagens educacionais e diante das necessidades do readequar os métodos de ensino em saúde, com as tecnologias remotas como ferramentas para atender a real necessidade da continuidade das aulas no formato não presencial (Bezerra, 2020). Portanto, se torna essencial a elaboração de estratégias de ensino remoto pelos professores de forma que atenda às necessidades de conhecimento dos discentes e consequentemente de maneira a contribuir para a formação e construção de um profissional de saúde capaz de atender com qualidade as demandas da sociedade.

Como principal implicação para pesquisas futuras deve-se criar a possibilidade de debates inclusivos sobre o ensino remoto na graduação em Enfermagem não somente para o momento que estamos vivendo mas que viabilizem diretivas importantes para um ensino híbrido e integrado com vistas a reflexões positivas a fim de contribuir de maneira eficiente para a formação desses discentes (Camacho, 2020).

Os aspectos positivos foram a disponibilidade do item "Ambientação" e "Apresentação da Disciplina" com vídeos explicativos que corroboraram para retirar as dúvidas e permitir o pleno andamento da disciplina. Também foi possível nas 
tarefas a abertura de espaço no ambiente virtual para dúvidas bem como nas aulas síncronas. Foi destaque o prazo para elaboração das atividades permitindo que os alunos estudassem em tempo hábil e disponibilizassem conteúdos educativos de qualidade.

Como limitações destacamos a indisponibilidade do Google Meet como problema técnico em alguns momentos no pacote Gsuíte. Além disso, em alguns instantes ocorreram a instabilidade do ambiente virtual de aprendizagem.

\section{Considerações Finais}

Com o objetivo de descrever as estratégias de planejamento e o desenvolvimento do ensino remoto sobre o processo de enfermagem na Pandemia da COVID-19 na disciplina Fundamentos de Enfermagem III foi possível vislumbrar a importância da interatividade entre o professor e o discente no transcurso da disciplina. Além disso, a disponibilidade docente de feedback das atividades ao discente deve ser uma constante que coadune com a proposta pedagógica das aulas ministradas visando interatividade e um aprendizado colaborativo.

Como contribuição relevante deste artigo trazemos a possibilidade de buscar a interatividade na educação remota nos seguintes aspectos: continuidade do planejamento; o docente como medidor do conhecimento; adequação do ambiente virtual de aprendizagem com as necessidades atuais do ensino remoto.

Como recomendação relevante há a importância do estabelecimento de estratégias de ensino articuladas com o conteúdo programático da disciplina através das ferramentas disponíveis no ambiente virtual.

\section{Referências}

Bastos, M. C. et al. (2020). Emergency remote teaching in nursing graduation: experience report during covid-19. Rev Min Enferm, $24: \mathrm{e}-1335$.

Bezerra, I. M. P. (2020). State of the art of nursing education and the challenges to use remote technologies in the time of corona virus pandemic. $J$ Hum Growth Dev, 30(1):141-47.

Brasil. Ministério da Educação. (2020). Portaria $n^{\circ}$ 343, de 17 de Março de 2020. Ministério da Educação. https://www.in.gov.br/en/web/dou/-/portaria-n343-de-17-de-marco-de-2020-248564376

Brasil. Ministério da Saúde. (2020). Coronavírus - covid 19: o que você precisa saber. Brasília: Ministério da Saúde. https://coronavirus.saude.gov.br/sobre-adoenca\#to-que-e-covid

Camacho, A. C. L. F. (2020). Editorial: Remote teaching in times of the COVID-19 pandemic: New experiences and challenges. Online Braz J Nurs, 19(4): 11.

Camacho, A. C. L. F., Joaquim, F. L., Menezes, H. F., \& Sant’ Anna, R. M. (2020). Tutoring in distance education in times of COVID-19: relevant guidelines. Research, Society and Development, 9(5) e30953151.

Carneiro, L.A., Rodrigues, W., França, G., \& Prata, D. N. (2020). Uso de tecnologias no ensino superior público brasileiro em tempos de pandemia COVID19. Research, Society and Development, v(8):1-18.

Castaman, A. S., \& Rodrigues, R. A. (2020) Educação a Distância na crise da COVID-19: um relato de experiência. Research, Society and Development, $9(6): 1-26$.

Conselho Federal de Enfermagem. (2009). Resolução COFEN 358/2009: Dispõe sobre a Sistematização da Assistência de Enfermagem e Implementação do Processo de Enfermagem em ambientes, públicos ou privados, em que ocorre o cuidado profissional de enfermagem, e dá outras providências. Brasília: DF. http://www.cofen.gov.br/resoluo-cofen-3582009_4384.html.

Costa, R. et al. (2020). Nursing teaching in covid-19 times: how to reinvent it in this context. Texto contexto - enferm, 29 :e20200202.

Ferguson, N. M., et al. (2020) Impact of non-pharmaceutical interventions (NPIs) to reduce COVID-19 mortality and healthcare demand. Imperial Ac Uk, 120 .

Fernandes, A. A. (2021). Ensino Remoto Emergencial e a Lógica do Cisne Negro. Research, Society and Development, 10(1): 1-11.

Lima, K. C., et al. (2020). A pessoa idosa domiciliada sob distanciamento social: possibilidades de enfrentamento à covid-19. Rev bras geriatra gerontol, $23(2) 1-3$.

Moreira, J. A., Henriques, S., \& Barros, D. M. V. (2020). Transitando de um ensino remoto emergencial para uma educação digital em rede, em tempos de pandemia. Dialogia, 1 (34): 351-364. 
Research, Society and Development, v. 10, n. 7, e7210716349, 2021

(CC BY 4.0) | ISSN 2525-3409 | DOI: http://dx.doi.org/10.33448/rsd-v10i7.16349

Pereira, A. S, Shitsuka, D. M., Parreira, F. J., \& Shitsuka, R. (2018). Metodologia da pesquisa científica. UFSM, NTE.

Qualls, N., et al. (2017). Community mitigation guidelines to prevent pandemic influenza - United States, 2017. MMWR Recomm and Rep, 66(1):1-34.

Rondini, C. A., Pedro, K. M, \& Dos Santos Duarte, C. (2020). Pandemia do Covid-19 e o ensino remoto emergencial: Mudanças na práxis docente. Interfaces Científicas-Educação, 10(1):41-57.

Teixeira, P. G., Lage, E. M., Junior, M. D. C., Corradi, W. J. B., \& Oliveira, C. L. (2020). The discipline primary attention to women's health, in the UFMG medicine course, mediated by technology. EmRede: Revista de Educação a Distância, 7(1):177-93.

UFF. Conselho de Ensino, Pesquisa e Extensão. (2020). Resolução n.160 de 2020: Regulamenta o ensino remoto emergencial, em caráter excepcional e temporário nos cursos de graduação presencial da Universidade Federal Fluminense e dá outras providências. Niterói: Universidade Federal Fluminense. http://uff.br/sites/default/files/news/arquivos/160-2020_ensino_remoto_e_emergencial_assinatura_digital_1.pdf

World Heath Organization. (2020). Geneva: Coronavirus disease 2019 (COVID-19): Situation Report -5. Coronavirus disease (COVID-19) pandemic. https://www.who.int/docs/default-source/coronaviruse/situation-reports/20200311-sitrep-51-covid-19.pdf?sfvrsn=1ba62e5710 